(C2019, Elsevier. Licensed under the Creative Commons Attribution-NonCommercialNoDerivatives 4.0 International http://creativecommons.org/about/downloads (c) 


\section{Liposome formulations of $o$-carborane for the boron neutron capture therapy of cancer}

Temidayo O.B. Olusanya, ${ }^{1}$ Gianpiero Calabrese, ${ }^{2}$ Dimitrios G. Fatouros, ${ }^{3}$ John Tsibouklis ${ }^{1}$ and James R. Smith ${ }^{1, *}$

${ }^{1}$ School of Pharmacy and Biomedical Sciences, University of Portsmouth, St Michael's Building, White Swan Road, Portsmouth PO1 2DT, UK

${ }^{2}$ School of Life Science, Pharmacy and Chemistry, Kingston University London, Penrhyn Road, Kingston-uponThames, Surrey KT1 2EE, UK

${ }^{3}$ Aristotle University of Thessaloniki, School of Pharmacy, Department of Pharmaceutical Technology, GR54124, Thessaloniki, Greece

* Corresponding Author: James R. Smith, Email: james.smith@port.ac.uk; Tel: +44 (0)23 9284 2556; Fax: +44 (0)239284 3565

Orcid Numbers:

Temidayo O.B. Olusanya 0000-0002-3565-2442

Gianpiero Calabrese 0000-0002-0137-4595

Dimitrios G. Fatouros $\quad$ 0000-0003-2361-4198

John Tsibouklis 0000-0001-5300-357X

James R. Smith 0000-0001-8805-3788 


\section{Abstract}

Based on the promise of liposomes as convenient vehicles for the transport of boronated agents for the boron neutron capture therapy (BCNT) of cancer, this paper reports a method for the formulation and characterisation of stable $o$-carborane-loaded liposomes (ca. $80-100 \mathrm{~nm}$ ) of dipalmitoyl-phosphatidylcholine (DPPC) or 1,2distearol-sn-glycerol-3-phosphocholine (DSPC). Preliminary pharmaceutical characterisation experiments have demonstrated the integrity of both DPPC and DSPC liposomal membranes in serum and in PBS and also indicate that these $o$-carborane-loaded liposomes are candidate carrier vehicles for further evaluation with a view to exploitation in BNCT.

Keywords: Boron neutron capture therapy, BNCT, Blood brain barrier, Cancer, Brain tumours, Carboranes, Liposomes 


\section{Introduction}

Boron neutron capture therapy (BNCT) uses a low-energy neutron beam directed at a tumour to bring about its selective destruction through interaction with administered boronated agents [1-3]. A localised nuclear fission reaction takes place within ${ }^{10} \mathrm{~B}$-containing tumour cells, which are consequentially destroyed by the produced $\alpha$ particles $(1.47 \mathrm{MeV})$ and recoiling ${ }^{7} \mathrm{Li}$ nuclei $(0.84 \mathrm{MeV})$ [4,5]; the therapeutically useful amount for BNCT is ca. 20-30 $\mu \mathrm{g}{ }^{10} \mathrm{~B} / \mathrm{g}$ tumour [6]. Although BNCT is considered suitable for many types of cancers (head and neck [7], hepatic [8], lung [9] and gastrointestinal [8]), most BNCT-related activities have been focused on brain tumours (gliomas), largely due to the risks associated with debulking [10].

Carboranes are caged polyhedral molecules that are regarded as promising boron-moieties agents for BNCT, owing to their high molar boron content, neutral charge and good stability [11-13]. These molecules are highly lipophilic [14] but readily amenable to functionalisation with hydrophilic moieties [15,16]. This functionalisation is rendered tuneable by the type (ortho- ' $o$-', meta- ' $m$-' or para ' $p$-') of progenitor carborane [17], all of which are biocompatible [18]. A growing body of evidence suggests that carboranes may be capable of being transported, although not intrinsically, across the blood-brain-barrier (BBB) [19] via small unilamellar vesicular (SUV, dia. $<100 \mathrm{~nm}$ ) liposomes [20,21]. Typically, these carriers are comprised of a lipid bilayer [22,23] that is stabilised through co-formulation with cholesterol molecules [24].

A diverse array of anti-cancer strategies involving liposomes continue to be developed [25,26]. Liu et al. reported a reduction in cell migration in triple negative breast cancer through use of liposomes functionalised with a C-X-C chemokine receptor type 4 (CSCR4, CD184) binding peptide (DV1) [27]. Liposomes immobilised with antibodies to target chronic inflamed endothelium, which plays a role in cancer and atherosclerosis [28]. Soft nanolipogels (NLGs, lipid bilayers encapsulating an alginate core) are reported to have higher cellular (neoplastic and non-neoplastic) uptake with respect to more elastic NLGs, although these particles have diameters of ca. 150 nm [29]. Huwyler et al. encapsulated daunomycin into PEGylated liposomes (85 nm), each coupled to 30 OX26 antibodies [30,31]. These are reported to accumulate successfully in brain tissue by overcoming the BBB limitation. Similar transport across the BBB is reported to have been achieved with liposomes $(<100 \mathrm{~nm})$ containing nerve growth factors (NGFs; 34\% encapsulation) [32]. For selective delivery to neoplastic tissues $[33,34]$, boronated agents may be encapsulated within the vacant polar inner space of liposomes or, in the case of polyhedral boranes, such as with o-carborane, incorporated within the lipid double-layers [33,35].

Rationalised by the promise of thin-film-method preparation [36], o-carborane-loaded, small $(<100 \mathrm{~nm}$ diameter), stable SUV liposomes to cross the BBB and to avoid recognition by macrophages [37], the current study focusses on structures of dipalmitoyl-phosphatidylcholine (DPPC) or 1,2-distearoyl-sn-glycero-3phosphocholine (DSPC) in co-formulation with cholesterol. Liposomal stability is assessed by means of $\zeta$ potential measurements and by evaluation of the retention of the hydrophilic marker calcein in phosphate-buffered saline (PBS, pH 7.4) and in human serum. $o$-Carborane incorporation is assessed spectrophotometrically by the displacement of Nile red method, and ${ }^{10} \mathrm{~B}$ content is quantified by the inductively coupled plasma - mass spectrometry (ICP-MS) technique.

\section{Experimental}

\subsection{Materials}

DPPC and DSPC were obtained from Lipoid ( $\geq 99 \%$; Ludwigshafen am Rhein, Germany). Potassium chloride (ACS Reagent), potassium phosphate dibasic $\left(\mathrm{K}_{2} \mathrm{HPO}_{4}\right.$; ACS Reagent), cholesterol ( $\left.\geq 99 \%\right)$, calcein (AR Grade), Nile red (Technical grade), Triton X-100 (Laboratory grade), conc. sulphuric acid (ACS reagent) and hydrogen peroxide (ACS reagent) and sephadex G-50 were provided by Sigma-Aldrich (Dorset, UK). Syringe filters (0.2 $\mu \mathrm{m}$, PES $25 \mathrm{~mm}$; GD/X sterile; Whatman), ethanol (Absolute), chloroform (ACS Reagent), sodium chloride (SLR grade), sodium phosphate monobasic (99\%; $\mathrm{NaH}_{2} \mathrm{PO}_{4}$ ), sodium hydroxide (ACS Reagent), hydrochloric acid (AR grade) and $o$-carborane (98\%; Alfa Aesar) were obtained from ThermoFisher Scientific (Loughborough, UK). $\mathrm{NaOH}(20 \%)$ and $\mathrm{HCl}(2 \mathrm{M})$ were prepared in the laboratory.

DPPC and DSPC liposomes incorporating specified amounts of $o$-carborane were prepared using the thin-film method.

\subsection{Preparation of phosphate buffered saline (PBS, pH 7.4)}

PBS (1 L) was made containing $\mathrm{NaCl}(8.00 \mathrm{~g}), \mathrm{KCl}(0.19 \mathrm{~g}), \mathrm{KH}_{2} \mathrm{PO}_{4}(0.2 \mathrm{~g}), \mathrm{Na}_{2} \mathrm{HPO}_{4}(1.7 \mathrm{~g})$ and adjusted to $\mathrm{pH} 7.4$.

\subsection{Preparation of calcein stock solution}


Calcein stock solution (50 mM) was prepared by dissolving calcein in distilled water with dropwise addition of $\mathrm{NaOH}$ until the powder was completely dissolved [19]. The $\mathrm{pH}$ of the calcein solution was adjusted to $\mathrm{pH}$ 7.4. The solution was then made up to $10 \mathrm{~mL}$, filtered, placed in an amber bottle wrapped in aluminium foil and stored in the refrigerator $\left(4^{\circ} \mathrm{C}\right)$.

\subsection{Preparation of serum stock solution from rat blood}

Plasma stock solution was made using whole blood: rat blood $(20 \mathrm{~mL})$ was placed in a beaker and placed in an incubator $\left(37^{\circ} \mathrm{C}, 30 \mathrm{~min}\right.$ ). A long Pasteur pipette was used to separate the thus clotted blood from the wall of the beaker. The clotted blood was transferred into separate Eppendorf tubes, cooled $\left(4{ }^{\circ} \mathrm{C}, 10 \mathrm{~min}\right)$ and centrifuged (3000 rpm, $10 \mathrm{~min}$ ) to effect the separation of plasma. The serum, which appeared as a clear yellowish liquid layer on top of the clotted blood, was transferred into new Eppendorf tubes (plastic pipette) and centrifuged (3000 rpm) for a further $10 \mathrm{~min}$. The separated serum was placed in Eppendorf tubes and stored in the freezer for future use.

\subsection{Preparation of Nile red stock solution}

For the assessment of liposome $\mathrm{o}$-carborane loading, a Nile red solution in $\mathrm{CHCl}_{3}$ (container wrapped in foil and stored at $4{ }^{\circ} \mathrm{C}$ ) was used to disperse the lipids before forming the thin film. The concentration of Nile red in the lipid dispersion was $2.5 \mu \mathrm{M}[19]$.

\subsection{Preparation of o-carborane stock solutions}

In accord with a literature method [21], the selected lipid (DPPC or DSPC; $15 \mathrm{mg}$ ) and $o$-carborane were mixed at molar ratios of 1:0.5, 1:1, 1:10, 1:20 and 1:40 to a lipid concentration of $5 \mathrm{mg} \mathrm{mL}^{-1}$. Respective concentrations for DPPC and DSPC solutions were $6.8 \mathrm{mM}$ and $6.3 \mathrm{mM}$ and corresponding concentrations for $o$-carborane were 3.4, 6.8, 68, 136 and $272 \mathrm{mM}$ and 3.2, 6.3, 63, 126 and $252 \mathrm{mM}$. Solutions were wrapped in foil and stored at 4 ${ }^{\circ} \mathrm{C}$.

\subsection{Preparation of DPPC/DSPC liposomes using the thin-film method}

DPPC and DSPC liposomes were prepared using the standard thin-film hydration method: DPPC or DSPC (250 $\mu \mathrm{L}$ ) from the stock solution (200 mg per $10 \mathrm{~mL}, 20 \mathrm{mg} \mathrm{mL}^{-1}$ ) [38] were placed into three separate flasks. This gave a lipid mass of $5 \mathrm{mg}$ (DPPC, $6.8 \mathrm{mM}$; DSPC, $6.3 \mathrm{mM}$ [19]), required for the low systemic toxicity and normal tissue uptake, equivalent to $c a .20 \mu \mathrm{g} /{ }^{10} \mathrm{~B} / \mathrm{g}$ tumour. The organic solvent was evaporated under reduced pressure (Buchi 461 rotary evaporator, Switzerland) at a temperature $10{ }^{\circ} \mathrm{C}>$ lipid phase transition temperature (chain melting temperature, $T_{C}=42{ }^{\circ} \mathrm{C}$ DPPC, $54{ }^{\circ} \mathrm{C}$ DSPC [39]) and then dried ( $\mathrm{N}_{2}$ stream) to yield thin films at the air-water interface. These were rehydrated at $60{ }^{\circ} \mathrm{C}$ with PBS (3 mL; buffer solution, pH 7.4) and dispersed (vortex) to produce empty liposomes [40].

Loaded liposomes were prepared using calcein $(3 \mathrm{~mL} ; 50 \mathrm{mM})$ that had been pre-warmed $>T_{c}$ of DPPC $\left(45^{\circ} \mathrm{C} ; 10 \mathrm{~min}\right.$ ) and added to the prepared thin film. This dispersion was vortexed (5 min) to assist uniform dispersion. To decrease the size of liposomal dispersions, the mixture was placed in the bath sonicator (30 min) $[38,41]$. The round-bottomed flask was placed at the air-water interface in the sonicator to ensure efficient particle size reduction [42].

For the preparation of SUVs, the suspension was subjected to probe sonication (120 s at $2 \mathrm{~s}$ intervals; Gex 400 Probe Sonicator, Germany) [43]. To remove of Ti fragments, multilamellar vesicles (MLVs) or liposomal aggregates, the liposome dispersion was centrifuged (5 min; $3000 \mathrm{rpm}$ ). Samples were then annealed [43] for at least $1 \mathrm{~h}$ at the liposome preparation temperature (above $T_{m} ; 50-60{ }^{\circ} \mathrm{C}$, water bath) [43] before loading them onto the gel-chromatography columns. For the addition of cholesterol, the lipid : cholesterol ratio was maintained at 2:1 [19].

\subsection{Preparation of DPPC/DSPC liposomes for fluorescence displacement, particle size measurements and ICP-MS}

As with the carborane-free liposomes, $o$-carborane-containing DPPC and DSPC liposomes were prepared using the thin-film hydration method. Specified volumes of $o$-carborane stock solution (e.g. for DPPC liposomes: 0, 12.5, 25, 250, 500 or $1000 \mu \mathrm{L}$; corresponding to $12.5 \mu \mathrm{L} \times 3.4 \mathrm{mM}=4.25 \times 10^{-8}$ moles of $o$-carborane), $\mathrm{CHCl}_{3}(1$ $\mathrm{mL})$ and Nile red $(1000 \mu \mathrm{L})$ were pipetted into a round-bottomed flask. The solvent was removed under reduced pressure (Buchi Rotavapor R) to yield a thin film. 


\subsection{Calcein stability measurements}

To render calcein-loaded vesicles osmotically stable, non-encapsulated calcein was separated from liposomes containing calcein on a Sephadex G-50 column (gel-permeation-chromatography, Anachem, Leicester, UK) using PBS (pH 7.4) as the eluent; pre-saturation of the column with each lipid, allowed recoveries > 94\% [19,44].

An aliquot of each solution $(40 \mu \mathrm{L})$ was placed into separate Eppendorf tubes containing PBS $(4 \mathrm{~mL} ; \mathrm{pH}$ 7.4) [43]. The fluorescence intensity ( $\lambda_{e m}=495 \mathrm{~nm}, \lambda_{e x}=520 \mathrm{~nm}$; Varian Inc., USA) was measured immediately $\left(t_{0}=0 \mathrm{~h}\right)$. Triton X-100 $(10 \% ; 400 \mu \mathrm{L})$ added and the tube agitated (electrical vortex: $\left.5 \mathrm{~s}, 2000 \mathrm{rpm}\right)$ to break down the liposomes and release the encapsulated calcein [43,45]. Fluorescence was recorded immediately $(0 \mathrm{~h})$ and again after $24 \mathrm{~h}$.

For fluorescence measurements in serum, a similar method was used. The combined volume of samples from the columns were divided by 4 and used for each reading, i.e., $200 \mu \mathrm{L}$ of sample was obtained from each column, and $50 \mu \mathrm{L}$ of serum used for each reading. The ratio of lipid : serum was therefore $1 \mathrm{~mL}: 40 \mu \mathrm{L}$. Fluorescence measurements (cuvette) and the procedure for adding Triton X-100 were performed as above, after adding the sample $(40 \mu \mathrm{L})$ to PBS $(4 \mathrm{~mL}, \mathrm{pH} 7.4)$.

Percent latency $(\% \mathrm{~L})$ and percent retention $(\% \mathrm{R})$ of liposomes (with and without incorporated cholesterol) in serum $\left(37^{\circ} \mathrm{C}\right.$ ) were calculated (equations (1) and (2)), at $0 \mathrm{~h}$ and at $24 \mathrm{~h}$.

$\% L=\frac{D_{f}\left(F_{a t}-F_{b t}\right)}{D_{f} F_{a t}} \times 100 \%$

where, $D_{f}=$ dilution factor (1.1), $F_{b t}=$ fluorescence value before adding Triton $\mathrm{X}-100, F_{a t}=$ fluorescence value after adding Triton X-100, and

$\% R=\frac{\% L_{t}}{\% L_{0}} \times 100 \%$

where, $\% L_{t}=\% L$ after $24 \mathrm{~h}$ and $\% L_{0}=\% L$ at the initial time point.

Statistical differences $(\mathrm{p}<0.05)$ between \%retention data were evaluated by means of the paired t-test.

\subsection{Nile red entrapment measurements}

The fluorescence intensities of liposomal solutions containing Nile red were measured under identical conditions to those employed for the calcein content measurements ( $\lambda_{e m}=495 \mathrm{~nm}, \lambda_{e x}=520 \mathrm{~nm}$; Varian Inc., USA).

\subsection{Particle sizing and $\zeta$-potential}

Dynamic light scattering (DLS; measurement angle, $173^{\circ}$ ) data were obtained for liposomes with or without entrapped $o$-carborane and electrophoresis measurements were performed using a Nano-ZS Zeta at $25^{\circ} \mathrm{C}(4 \mathrm{~mW}$ He-Ne laser $\lambda=633 \mathrm{~nm}$, photodiode detector; Malvern Instruments, UK). PDI and $\zeta$-potential were determined at $25{ }^{\circ} \mathrm{C}$.

\subsection{ICP-MS Boron analysis}

In boron-free glass vials, an aliquot of conc. $\mathrm{H}_{2} \mathrm{SO}_{4}(500 \mu \mathrm{L})$ was added to each of the liposome solutions (600 $\mu \mathrm{L})$ in each $o$-carborane-containing liposome formulation. These solutions, which were observed to became hot and progressively darker, were allowed to stand until they cooled to room temperature $\left(<24{ }^{\circ} \mathrm{C}\right) . \mathrm{H}_{2} \mathrm{O}_{2}(100 \mu \mathrm{L})$ was added to each tube. When solutions became decolourised, volumes were adjusted to $2 \mathrm{~mL}$ by the addition of distilled water $(800 \mu \mathrm{L})$. The ${ }^{10} \mathrm{~B}$ content of the mineralised samples and that of the supernatant were determined using ICP-MS (700 Series; Agilent Technologies, Santa Clara, CA, USA) operating at $1550 \mathrm{~W}$, with a carrier gas flow rate of $0.91 \mathrm{~L} \mathrm{~min}^{-1}$, make up gas flow of $0.24 \mathrm{~L} \mathrm{~min}^{-1}$ and a nebuliser pump rate of 0.1 rps. Beryllium and ${ }^{10} \mathrm{~B}$ standard solutions (1000 ppm) were used in the calibration.

\subsection{Scanning electron microscopy}

Aliquots of solutions containing DSPC liposomes $(5 \mu \mathrm{L})$, either unloaded or $o$-carborane $(1000 \mu \mathrm{L})$ loaded, were placed on the surface of freshly-cleaved muscovite mica (Agar Scientific, Stansted, Essex, UK) and left to dry for 2 min. The surface was rinsed with distilled water, dried in a $\mathrm{N}_{2}$ stream and sputter-coated with Au/Pd in an Argon atmosphere (<0.2 Torr, 18 mA for 5-10 min; Polaron E5000 SEM coating-unit, Quorum Technologies Ltd., East Grinstead, UK). SEM imaging was performed immediately using a JEOL JSM-6060LV SEM instrument 
(resolution $=4.5 \mathrm{~nm}$, acceleration voltage $=15 \mathrm{kV}$ ). Mean particle sizes were obtained through the deployment of a scale bar.

\subsection{Atomic force microscopy}

Liposome samples were prepared as for SEM, but without Au/Pd coating. Atomic force microscopy (AFM) studies were carried out using a Multi-Mode / NanoScope IV scanning probe microscope, Bruker, Santa Barbara, CA, USA and were performed in air under ambient conditions $\left(T=23^{\circ} \mathrm{C}, \mathrm{RH}=21 \%\right)$ using the J-scanner (max. $\mathrm{xy}=200 \mu \mathrm{m})$. Scanning was performed in Tapping mode using Si cantilevers with integrated tips $(t=3.6-5.6$ $\mu \mathrm{m}, l=140-180 \mu \mathrm{m}, w=48-52 \mu \mathrm{m}, v_{0}=288-338 \mathrm{kHz}, k=12-103 \mathrm{~N} \mathrm{~m}^{-1}, R<7 \mathrm{~nm}$; model: OTESPA, Bruker, France), and an RMS amplitude of $0.8 \mathrm{~V}$. The images were subsequently processed and dimensions (particle diameters) measured using NanoScope Analysis software (V1.4, Bruker, Santa Barbara, CA, USA).

\subsection{Statistical measurements}

One-way ANOVA and posthoc (Tukey) analyses were performed using SPSS (Version 24; IBM, Armonk, NY, USA) with the exception of the retention results, which were analysed using GraphPad Prism (Version 7.03; GraphPad Software, La Jolla, CA, USA).

\section{Results and discussion}

\subsection{Particle sizing, PDI and $\zeta$-potential}

To minimise particle size, liposome formulations were probe sonicated twice. The effect of re-probing (before and after the second probe, $5 \mathrm{~min}$ ) on particle size, PDI and $\zeta$-potential was investigated for the $o$-carboraneloaded DPPC and DSPC liposomes. The data $(\mathrm{n}=3)$ show that re-probing reduces the average particle sizes of both DPPC and DSPC liposomes (Table 1) to a range that is deemed suitable for drug delivery across the BBB (< $100 \mathrm{~nm}$ ) [46]. Particle sizes were seen to increase with increasing o-carborane loading. The diameters of the longer-lipid-chain-length DSPC liposomes were observed to be larger than those of DPPC structures. Indicative of monodisperse and homogenous particle size distributions, PDI values for all liposomes were $<0.5$. $\zeta$-Potentials of between -30 and $+30 \mathrm{mV}$, probably due to the high ionic strength of the PBS medium [19], highlight the likelihood of some particle agglomeration. Notably, Awad and co-workers attributed an observed sigmoidal decrease in $\zeta$-potential (from -5 to $-40 \mathrm{mV}$ ) with increasing concentrations of sodium borocaptate (BSH) to the interaction between the boron species and the lipid bilayer [45].

\subsection{Stability of liposome properties after one week}

Since the $\zeta$-potentials of the liposomes indicated the likelihood of agglomeration, particle sizes were re-measured after 1 week of storage in the refrigerator $\left(3-5^{\circ} \mathrm{C}\right)$. Liposomes were probe sonication once before storage, but not re-probed after the storage period: particle sizes and PDI values are presented in Table 2.

Prior to storage, particle size measurements indicated that increasing $o$-carborane content increases the sizes of both DPPC and DSPC liposomes. At the lower range of the specified concentrations, particles sizes were within the acceptable $(100 \mathrm{~nm})$ range. For DSPC liposomes, particle sizes increased dramatically with increased loadings of $o$-carborane. (PDI values were generally $<0.5$, reflecting high monodispersity and homogeneity, but some DSPC liposomes of high $o$-carborane content breached this limit.) On storage, liposome sizes generally increased but in a manner that is not linked directly to $o$-carborane content.

\subsection{AFM studies}

AFM was used to investigate the long-term stability of $o$-carborane-containing liposomes. To facilitate the observation of changes in the morphology of liposomes and to investigate agglomeration, the liposomes were reprobed prior to measuring sizes with the AFM. Line profiles were used to obtain particle sizes (diameters) from the images of unloaded and loaded DPPC and DSPC liposomes (max. lipid : o-carborane 1:40; Fig. 1; Table 3); these were obtained after 1, 19, 35, 49 and 63 days after preparation. Loaded liposomes appeared intact after 63 days of storage, indicating the suitability of the formulation as a BNCT carrier of $o$-carborane. Particle diameters rather than heights were measured, since the latter are known to be subject to an artefact resulting from possible compression of biomaterial under the applied load of the AFM tip in TappingMode [47] (as reflected in the lowerthan-expected z-scales in Fig. 1). 


\subsection{SEM studies}

To investigate liposome morphology further and to complement particle size data obtained with the zeta sizer and with AFM, particle diameters were obtained from SEM images (Fig. 2). Both the unloaded and $o$-carboraneloaded (max. lipid : $o$-carborane 1:40) liposomes were seen to be spherical and featureless. Loaded structures had somewhat larger mean diameters than unloaded DSPC liposomes (267 \pm 90 and $201 \pm 53 \mathrm{~nm}$, respectively; $\mathrm{n}=$ 30 per group; $\mathrm{p}<0.05$ ). Sizes were in the range measured using laser diffraction methods (Malvern Nanosizer). These findings are consistent with a literature report that o-carborane-loaded 1,2-dimyristoyl-sn-glycero-3phosphocholine (DMPC) liposomes were larger than those of their unloaded congeners [19].

\subsection{Stabilisation of liposomes with cholesterol and serum}

To assess the stability of the liposome formulations in physiologically relevant media, the leaching from these vehicles was investigated of the water-soluble, hydrophilic fluorescent marker calcein. Towards an understanding of the effect of the cholesterol stabilising agent in improving the stability of DPPC and DSPC liposomes, the effect of cholesterol inclusions was investigated; cholesterol is known to stabilise liposome formations by increasing rigidity and preventing leakage [24]. Studies monitored the release of calcein from liposomes (in the absence of $o$-carborane) following treatment with Triton X-100, which is known to disrupt the lipid bilayer. To this end, calcein-containing DPPC and DSPC liposomes were prepared and particle sizes (Fig. 3), PDI values and $\zeta$-potentials were determined in PBS medium and in rat serum $\left(37^{\circ} \mathrm{C}\right)$.

In all cases, DSPC liposomes were observed to be larger than their DPPC congeners $(\mathrm{p}<0.05)$. In the absence of cholesterol, both types of liposomes exhibited larger diameter particles in serum than in PSB buffer. In accord with expectation, the incorporation of cholesterol into the liposomes in serum was seen to have an augmenting effect on size (cholesterol is known to effect increases in size by interfacing between the lipid bilayers [24]). PDI values, $\zeta$-potentials (typically 0.4 and $-0.4 \mathrm{mV}$ for DPPC and DSPC, respectively) did not appear to be influenced by liposome type or by the extent of $o$-carborane loading.

To assess membrane integrity (stability), the retention of encapsulated calcein was evaluated for both types of DPPC and DSPC liposomes (with or without cholesterol). Measurements were made prior to and at $24 \mathrm{~h}$ following treatment with Triton X-100 (which disrupts the lipid bilayers) in PBS buffer (pH 7.4; Fig. 4). No statistical difference was found between the retention values of DPPC and DSPC liposomes in the absence or in the presence of cholesterol, irrespective of whether the experiment was conducted in PBS or in serum (ANOVA, $\mathrm{p}=0.4929$ ). Liposome stability appears to be little influenced by the type of liposomal constitutional unit (DPPC or DSPC). Also, it is strongly indicated that cholesterol does not bestow increased liposomal stability in PBS; and that the cholesterol-containing liposomes are similarly stable in serum and in PBS. Over the 24 hour timescale, there was no significant indication that liposomes in serum exhibit signs of degradation.

\subsection{Nile red experiments}

To assess if $o$-carborane had been incorporated into the liposomes in sufficient amounts for use in BNCT, Nile red, a fluorescent marker, was utilised as a displacement agent for $o$-carborane. DPPC and DSPC liposomes containing a fixed amount of Nile red $(2.5 \mu \mathrm{M})$ and specified amounts of $o$-carborane were prepared and characterised in terms of particle size, PDI and $\zeta$-potential (Table 4). The experiments demonstrate that liposomes were again prepared at the desired particle size $(<100 \mathrm{~nm})$. DPPC particles were seen to be smaller than DSPC liposomes; PDI and $\zeta$-potential values were consistent with those of other congener liposomes. Since the mean particle size increased with increasing o-carborane content, as observed previously, it would be reasonable to assume that the increasingly higher contents of $o$-carborane was successfully encapsulated in the liposomes. Fluorescence intensity measurements on liposome formulations, validated the technique: entrapped Nile red was indicated to occupy the available space of liposomes that had not been filled to saturation with $o$-carborane, as demonstrated by the inverse relationship between fluorescence intensity and $o$-carborane content (Fig. 5). Although the evidence is indirect and the data may only be regarded as semi-quantitative, there is strong evidence that the entire amount of $o$-carborane used in the preparation of the liposomes had been entrapped in all cases. To quantify $o$-carborane incorporation, the boron content was determined using ICP-MS

\subsection{ICP-MS measurements of o-carborane incorporation}

For both DPPC and DSPC liposomes $\left(\mathrm{R}^{2}=0.987\right.$ and 0.992, respectively; Fig. 6$)$ the data show a clear match between the incorporated $o$-carborane content and that which is determined experimentally by ICP-MS. 


\section{Conclusions}

Employment of the thin film method afforded o-carborane-containing DPPC or DSPC SUV liposomes with particle diameters of $c a$. $80-100 \mathrm{~nm}$. Liposomes of DSPC had slightly larger average particle sizes than their DPPC congeners. For both DPPC and DSPC liposomes, average particle diameter increased with increasing amounts of entrapped $o$-carborane. All liposomes exhibited a monodispersed and homogeneous particle size distribution (PDI < 0.5). In PBS, both DPPC and DSPC probe-sonication-prepared liposomes exhibited $\zeta$ potentials that are in a range indicative of instability (between -30 and $+30 \mathrm{mV}$ ) but the re-probing of samples has been shown to effect the formation of particles at the desirable size range $(<100 \mathrm{~nm})$ that exhibit good stability on storage at $3-5{ }^{\circ} \mathrm{C}$ for at least one week. The effect of re-probing on stability was further demonstrated by AFM studies, which have shown that the loaded liposomes remain generally intact after 63 days of storage. Percentage retention experiments using a fluorescent marker (calcein) have shown that the integrity of the liposomal membrane in serum is high for both DPPC and DPPC liposomes that had been prepared using cholesterol as the stabilising agent. A combination of ICP-MS determinations and experiments involving the coentrapment into the liposomes of $o$-carborane and Nile Red have shown that in all cases boron content was quantitatively consistent with the amount that had been formulated into each liposomal sample. Future studies should be directed to the incorporation of cancer-targeted boron-compounds within the SUV liposomes and an investigation of their efficacy in vitro.

\section{References}

[1] R.L. Moss, Critical review, with an optimistic outlook, on boron neutron capture therapy (BNCT), Appl. Radiation Isotopes 88 (2014) 2-11.

[2] G. Calabrese, A. Daou, A. Rova, E. Tseligka, I.S. Vizirianakis, D.G. Fatouros, J. Tsibouklis, Boron-containing delocalised lipophilic cations for the selective targeting of cancer cells, Med. Chem. Comm. 8(1) (2017) 67-72.

[3] Y.H. Zhu, N.S. Hosmane, Nanostructured boron compounds for cancer therapy. Pure Appl Chem 2018; 90(4): 653-663.

[4] R.F. Barth, J.A. Coderre, M.G.H. Vicente, T.E. Blue, Boron neutron capture therapy of cancer: Current status and future prospects, Clin. Cancer Res. 11(11) (2005) 3987-4002.

[5] N.S. Hosmane, Z. Yinghuai, J.A. Maguire, W. Kaim, M. Takagaki, Nano and dendritic structured carboranes and metallacarboranes: From materials to cancer therapy, J. Organometal. Chem. 694(11) (2009) 1690-1697.

[6] M.F. Hawthorne, New horizons for therapy based on the boron neutron capture reaction, Mol. Med. Today 4(4) (1998) 174-181.

[7] T. Aihara, N. Morita, N. Kamitani, N. Kumada, K. Ono, J. Hiratsuka, T. Harada, BNCT for advanced or recurrent head and neck cancer, Appl. Radiation Isotopes 88 (2014) 12-15.

[8] H. Yanagie, S. Higashi, K. Seguchi, I. Ikushima, K. Oyama, Y. Nonaka, S. Maruyama, R. Hatae, T. Sairennji, S. Takahashi, M. Suzuki, S. Masunaga, T. Kinashi, Y. Sakurai, H. Tanaka, A. Maruhashi, K. Ono, J. Nakajima, M. Ono, H. Takahashi, M. Eriguchi, Pilot clinical study of Boron Neutron Capture Therapy for recurrent hepatic cancer and gastric cancer. In: Presented at the $15^{\text {th }}$ International Congress on Neutron Capture Therapy, Tsukuba, Japan, September 10-14, 2012.

[9] M. Suzuki et al., Reirradiation for locally recurrent lung cancer in the chest wall with Boron Neutron Capture Therapy (BNCT): a case report. In: Presented at the 15th International Congress on Neutron Capture Therapy, Tsukuba, Japan, September 10-14, 2012.

[10] H. Zhu, L. Leiss, N. Yang, C.B. Rygh, S.S. Mitra, S.H. Cheshier, I.L. Weissman, B. Huang, H. Miletic, R. Bjerkvig, P.O. Enger, X. Li, J. Wang, Surgical debulking promotes recruitment of macrophages and triggers glioblastoma phagocytosis in combination with CD47 blocking immunotherapy, Oncotarget 8(7) (2017) 1214512157.

[11] G. Calabrese, A. Daou, E. Barbu E, J. Tsibouklis, Towards carborane-functionalised structures for the treatment of brain cancer, Drug Discovery Today 23(1) (2018) 63-75.

[12] M.F. Hawthorne, The role of chemistry in the development of boron neutron capture therapy of cancer, Angew. Chem. Int. Ed. 32(7) (1993) 950-984.

[13] J.R. Smith, T.O.B. Olusanya, A.J.S. Owens, E. Tseligka, I.S. Vizirianakis, J. Tsibouklis, Formulation and characterisation of spray-dried o-carborane/poly(vinylpyrrolidone) for boron neutron capture therapy of liver and lung cancer, J. Innov. Pharm. Biol. Sci. 4(4) (2017) 9-15.

[14] S.E.A. Gratton, M.C. Parrott, A. Adronov, Preparation of carborane-containing polymers by atom transfer radical polymerization, J. Inorg. Organometal. Polym. Mater. 15(4) (2005) 469-475.

[15] B.D. Anderson, Prodrugs for improved CNS delivery, Adv. Drug Delivery Rev. 19(2) (1996) 171-202.

[16] K. Hoste, K. De Winne, E. Schacht, Polymeric prodrugs, Int. J. Pharm. 277(1-2) (2004) 119-131. 
[17] K. Ohta, T. Goto, S. Fujii, M. Kawahata, A. Oda, S. Ohta, K. Yamaguchi, S. Hirono, Y. Endo, Crystal structure, docking study and structure-activity relationship of carborane-containing androgen receptor antagonist 3-(12-hydroxymethyl-1,12-dicarba-closo-dodecaboran-1-yl)benzonitrile, Bioorg. Med. Chem. 19(11) (2011) 3540-3548.

[18] C. Di Meo, L. Panza, F. Campo, D. Capitani, L. Mannina, A. Banzato, M. Rondina, A. Rosato, V. Crescenzi, Novel types of carborane-carrier hyaluronan derivatives via "click chemistry", Macromol. Biosci. 8(7) (2008) 670-681.

[19] D. Theodoropoulos, A. Rova, J.R. Smith, E. Barbu, G. Calabrese, I.S. Vizirianakis, J. Tsibouklis, D.G. Fatouros, Towards boron neutron capture therapy: The formulation and preliminary in vitro evaluation of liposomal vehicles for the therapeutic delivery of the dequalinium salt of bis-nido-carborane, Bioorg. Med. Chem. Lett. 23(22) (2013) 6161-6166.

[20] S.G. Antimisiaris, P. Kallinteri, D.G. Fatouros, Liposomes and drug delivery, Pharmaceutical Sciences Encyclopedia: Drug Discovery, Development, and Manufacturing (2010).

[21] G.V. Betageri, S.A. Jenkins, D.L. Parsons, Liposome Drug Delivery Systems, Technomic Publishing Company Inc, Lancaster, UK (1993).

[22] A.D. Bangham, M.M. Standish, J.C. Watkins, Diffusion of univalent ions across the lamellae of swollen phospholipids, J. Mol. Biol. 13(1) (1965) 238-252.

[23] V.P. Torchilin, Recent advances with liposomes as pharmaceutical carriers, Nature Rev. Drug Discovery 4(2) (2005) 145-160.

[24] M.J. Ostro, P.R. Cullis, Use of liposomes as injectable-drug delivery systems, Am. J. Hospital Pharm. 46(8) (1989) 1576-1587.

[25] T.O.B. Olusanya, R.R.H. Ahmad, D.M. Ibegbu, J.R. Smith, A.A. Elkordy, Liposomal drug delivery systems and anticancer drugs, Molecules 23(4) (2018) 907.

[26] R.-D. Hofheinz, S.U. Gnad-Vogt, U. Beyer, A. Hochhaus, Liposomal encapsulated anti-cancer drugs, AntiCancer Drugs 16(7) (2005) 691-707.

[27] D. Liu, P. Guo, C. McCarthy, B. Wang, Y. Tao, D. Auguste, Peptide density targets and impedes triple negative breast cancer metastasis, Nature Commun. 9 (2018) 2612.

[28] D. Almeda, B. Wang, D.T. Auguste, Minimizing antibody surface density on liposomes while sustaining cytokine-activated EC targeting, Biomaterials 41 (2015) 37-44.

[29] P. Guo, D. Liu, K. Subramanyam, B. Wang, J. Yang, J. Huang, D.T. Auguste, M.A. Moses, Nanoparticle elasticity directs tumor uptake, Nature Commun. 9 (2018) 130.

[30] J. Huwyler, D. Wu, W.M. Pardridge, Brain drug delivery of small molecules using immunoliposomes, Proc. Natl. Acad. Sci. USA 93(24) (1996) 14164-14169.

[31] M.J. Ostro, P.R. Cullis, Use of liposomes as injectable-drug delivery systems, Am. J. Hospital Pharm. 46(8) (1989) 1576-1587.

[32] Y. Xie, L. Ye, X. Zhang, W. Cui, J. Lou, T. Nagai, X. Hou, Transport of nerve growth factor encapsulated into liposomes across the blood-brain barrier: in vitro and in vivo studies, J. Controlled Rel. 105(1) (2005) 106119.

[33] H. Nakamura, Chapter 10 - Liposomal Boron Delivery for Neutron Capture Therapy, in Methods in Enzymology, Nejat D (Ed.), Academic Press, MA, USA, (2009), pp. 179-208.

[34] G. Calabrese, J.J. Nesnas, E. Barbu, D.G. Fatouros, J. Tsibouklis, The formulation of polyhedral boranes for the boron neutron capture therapy of cancer, Drug Discovery Today 17(3-4) (2012) 153-159.

[35] H. Yanagie, T. Tomita, H. Kobayashi, Y. Fujii, T. Takahashi, K. Hasumi, H. Nariuchi, M. Sekiguchi, Application of boronated anti-CEA immunoliposome to tumour cell growth inhibition in in vitro boron neutron capture therapy model, Br. J. Cancer 63(4) (1991) 522-526.

[36] D. Papahadjopoulos, J.C. Watkins, Phospholipid model membranes. II. Permeability properties of hydrated liquid crystals, Biochim. Biophys. Acta Biomembranes 135(4) (1967) 639-652.

[37] G.M. Barratt, Therapeutic applications of colloidal drug carriers, Pharm. Sci. Technol. Today 3(5) (2000) 163-171.

[38] D.G. Fatouros, S.G. Antimisiaris, Effect of amphiphilic drugs on the stability and zeta-potential of their liposome formulations: a study with prednisolone, diazepam, and griseofulvin, J. Colloid Interface Sci. 251(2) (2002) 271-277.

[39] T.M. Koyama, C.R. Stevens, E.J. Borda, K.J. Grobe, D.A. Cleary, Characterizing the gel to liquid crystal transition in lipid-bilayer model systems, Chem. Ed. 5(3) (2000) S1430-S4171.

[40] D.G. Fatouros, G. Calabrese, E. Barbu, M. Roldo, A.G. Fatourou, Boron neutron capture therapy: active agents and lipid carriers, Vizirianakis I (Ed.), Handbook of Personalized Medicine: Advances in Nanotechnology, Drug Delivery and Therapy. Pan Stanford Publishing, Singapore, (2013), pp. 109-121. ISBN 9789814411196 [41] J.Q. Zhang, Z.R. Zhang, H. Yang, Q.Y. Tan, S.R. Qin, X.L. Qiu, Lyophilized paclitaxel magnetoliposomes as a potential drug delivery system for breast carcinoma via parenteral administration: in vitro and in vivo studies, Pharm. Res. 22(4) (2005) 573-583. 
[42] T. Peters, Development and in vitro testing of liposomal gadolinium-formulations for neutron capture therapy of glioblastoma multiforme. Thesis, Pharmazie und Geowissenschaften der Johannes Gutenberg-Universität, Mainz, (2013).

[43] S. Piperoudi, D.G. Fatouros, P.V. Ioannou, P. Frederik, S.G. Antimisiaris, Incorporation of PEG-lipids in arsonoliposomes results in formation of highly stable arsenic-containing vesicles, Chem. Phys. Lipids 139(2) (2006) 96-106.

[44] J.C.M. Stewart, Colorimetric determination of phospholipids with ammonium ferrothiocyanate, Anal Biochem 104(1) (1980) 10-14.

[45] D. Awad, L. Damian, M. Winterhalter, G. Karlsson, K. Edwards, D. Gabel, Interaction of Na2B12H11SH with dimyristoyl phosphatidylcholine liposomes, Chem. Phys. Lipids 157(2) (2009) 78-85.

[46] A.R. Jones, E.V. Shusta, Blood-brain barrier transport of therapeutics via receptor-mediation, Pharm. Res. 24(9) (2007) 1759-1771.

[47] J.R. Smith, Z. Maherally, S.C. Higgins, Q. An, H.L. Fillmore, G.J. Pilkington, AFM observation of heightened cell periphery of high-grade glioblastoma cell lines, Bionanoscience 6(1) (2016) 47-53. 


\section{List of Figures and Tables}

Table 1. Effect on particle size, PDI and $\zeta$-potential of the second probe sonication on DPPC and DSPC liposomes containing specified loadings of $o$-carborane $(n=3)$.

Table 2. Mean particle sizes and PDI values of (a) DPPC and (b) DSPC liposomes before and after storage at 3$5{ }^{\circ} \mathrm{C}$ for 1 week ( $\mathrm{n}=3$; SD = standard deviation).

Table 3. Time variation of particle sizes (diameters) of DPPC and DSPC liposomes, both $o$-carborane-free and $o$-carborane-loaded (max. investigated lipid : $o$-carborane 1:40), as determined using AFM.

Table 4. Particle size, PDI and $\zeta$-potential values of DPPC and DSPC liposomes incorporating Nile red and specified $o$-carborane loadings $(\mathrm{n}=2)$.

Fig. 1. Representative AFM images of $o$-carborane-free and $o$-carborane-loaded liposomes: (a) $o$-carborane-free DPPC, obtained after 1 day; (b) $o$-carborane-loaded DPPC, obtained after 1 day; (c) o-carborane-loaded DPPC, obtained after 49 days; (d) $o$-carborane-loaded DSPC, obtained after 49 days. For each: $\mathrm{n}=4$; loading ratio = $1: 40$

Fig. 2. SEM images of DSPC liposomes: $o$-carborane-free (a,b,c) and o-carborane-loaded (1:40 ratio; d,e,f) on mica.

Fig. 3. Particle size variation for different formulations of calcein-incorporating DPPC and DSPC liposomes (with or without cholesterol) in PBS and in serum (error bar $=\mathrm{SD} ; \mathrm{n}=3$ ).

Fig. 4. Retention of DPPC and DSPC liposomal dispersions (formulated with or without cholesterol) in PBS and in serum. Formulations were incubated at $37^{\circ} \mathrm{C}$. Data are presented as mean $\pm \operatorname{SD}(n=3)$.

Fig. 5. Nile red incorporation into (a) DPPC and (b) DSPC liposomes loaded at specified lipid : $o$-carborane ratios.

Fig. 6. Comparison of detected vs. incorporated loadings of $o$-carborane into DPPC and DSPC liposomes as determined using ICP-MS. Ratios are lipid : $o$-carborane. 
Figures and Tables

Table 1.

\begin{tabular}{|c|c|c|c|c|c|c|c|c|}
\hline \multicolumn{2}{|c|}{ Lipid : o-carborane } & & $1: 40$ & $1: 20$ & $1: 10$ & $1: 1$ & $1: 0.5$ & $1: 0$ \\
\hline \multicolumn{9}{|l|}{ (a) DPPC } \\
\hline \multirow[t]{2}{*}{1} & Before & $d / \mathrm{nm}$ & 547.9 & 234.6 & 99.3 & 56.7 & 56.2 & 55.7 \\
\hline & & PDI & 1.000 & 0.608 & 0.318 & 0.204 & 0.352 & 0.242 \\
\hline \multirow[t]{3}{*}{1} & After & $d / \mathrm{nm}$ & 69.0 & 65.9 & 60.5 & 58.8 & 58.5 & 57.1 \\
\hline & & PDI & 0.105 & 0.116 & 0.48 & 0.155 & 0.266 & 0.273 \\
\hline & & $\zeta / \mathrm{mV}$ & -0.365 & -2.24 & -1.04 & -0.416 & 1.53 & -1.39 \\
\hline \multirow[t]{2}{*}{2} & Before & $d / \mathrm{nm}$ & 114.5 & 106.9 & 88.74 & 85.04 & 65.35 & 61.75 \\
\hline & & PDI & 0.479 & 0.544 & 0.245 & 0.341 & 0.233 & 0.243 \\
\hline \multirow[t]{3}{*}{2} & After & $d / \mathrm{nm}$ & 81.5 & 80.6 & 70.1 & 64.8 & 63.0 & 60.7 \\
\hline & & PDI & 0.357 & 0.413 & 0.168 & 0.199 & 0.115 & 0.259 \\
\hline & & $\zeta / \mathrm{mV}$ & -4.31 & -16.30 & -16.50 & -24.50 & -35.20 & -28.20 \\
\hline \multirow[t]{2}{*}{3} & Before & $d / \mathrm{nm}$ & 1046.0 & 136.4 & 99.9 & 89.2 & 78.6 & 74.3 \\
\hline & & PDI & 1.000 & 0.445 & 0.442 & 0.256 & 0.251 & 0.311 \\
\hline \multirow[t]{3}{*}{3} & After & $d / \mathrm{nm}$ & 75.5 & 50.2 & 44.1 & 43.5 & 42.6 & 42.1 \\
\hline & & PDI & 0.171 & 0.243 & 0.3000 & 0.260 & 0.222 & 0.239 \\
\hline & & $\zeta / \mathrm{mV}$ & -2.52 & -13.50 & -13.10 & -22.90 & -20.80 & -20.40 \\
\hline Mean & After & $d / \mathrm{nm}$ & $75.3 \pm 6.2$ & $65.6 \pm 15.2$ & $58.2 \pm 13.2$ & $55.7 \pm 11.0$ & $54.7 \pm 10.7$ & $53.3 \pm 9.9$ \\
\hline \multirow{2}{*}{ \pm SD } & & PDI & $0.21 \pm 0.13$ & $0.26 \pm 0.15$ & $0.32 \pm 0.16$ & $0.210 .26 \pm 0.05$ & $0.20 \pm 0.08$ & $0.26 \pm 0.02$ \\
\hline & & $\zeta / \mathrm{mV}$ & $-2.40 \pm 1.98$ & $-10.68 \pm 7.44$ & $-10.21 \pm 8.12$ & $-15.94 \pm 13.47$ & $-18.16 \pm 18.51$ & $-16.66 \pm 13.79$ \\
\hline \multicolumn{9}{|l|}{ (b) DSPC } \\
\hline \multirow[t]{2}{*}{1} & Before & $d / \mathrm{nm}$ & 150.5 & 146.9 & 145.1 & 94.7 & 93.2 & 82.8 \\
\hline & & PDI & 0.280 & 0.217 & 0.179 & 0.136 & 0.177 & 0.215 \\
\hline \multirow[t]{3}{*}{1} & After & $d / \mathrm{nm}$ & 111.0 & 105.8 & 96.51 & 93.5 & 82.7 & 59.5 \\
\hline & & PDI & 0.167 & 0.220 & 0.180 & 0.169 & 0.159 & 0.262 \\
\hline & & $\zeta / \mathrm{mV}$ & -3.92 & -5.46 & -11.80 & -23.7 & -20.20 & -7.88 \\
\hline \multirow[t]{2}{*}{2} & Before & $d / \mathrm{nm}$ & 150.8 & 136.9 & 132.9 & 91.0 & 81.7 & 79.0 \\
\hline & & PDI & 0.220 & 0.131 & 0.186 & 0.092 & 0.135 & 0.176 \\
\hline \multirow[t]{3}{*}{2} & After & $d / \mathrm{nm}$ & 98.3 & 97.3 & 96.3 & 90.1 & 76.7 & 71.3 \\
\hline & & PDI & 0.186 & 0.204 & 0.160 & 0.143 & 0.098 & 0.134 \\
\hline & & $\zeta / \mathrm{mV}$ & -4.37 & -12.40 & -17.40 & -3.21 & -31.50 & -22.30 \\
\hline \multirow[t]{2}{*}{3} & Before & $d / \mathrm{nm}$ & 588.4 & 130.3 & 79.7 & 73.0 & 86.9 & 80.5 \\
\hline & & PDI & 0.956 & 0.487 & 0.215 & 0.163 & 0.212 & 0.186 \\
\hline \multirow[t]{3}{*}{3} & After & $d / \mathrm{nm}$ & 85.8 & 81.4 & 64.3 & 39.3 & 39.0 & 38.8 \\
\hline & & PDI & 0.209 & 0.285 & 0.249 & 0.307 & 0.304 & 0.246 \\
\hline & & $\zeta / \mathrm{mV}$ & -2.06 & -16.00 & -17.90 & -2.99 & -26.80 & -21.00 \\
\hline \multirow{3}{*}{$\begin{array}{l}\text { Mean } \\
\pm S D\end{array}$} & After & $d / \mathrm{nm}$ & $98.4 \pm 12.6$ & $94.9 \pm 12.4$ & $85.7 \pm 18.5$ & $74.3 \pm 30.4$ & $66.1 \pm 23.7$ & $56.6 \pm 6.5$ \\
\hline & & PDI & $0.19 \pm 0.02$ & $0.24 \pm 0.04$ & $0.20 \pm 0.05$ & $0.21 \pm 0.01$ & $0.19 \pm 0.11$ & $0.21 \pm 0.07$ \\
\hline & & $\zeta / \mathrm{mV}$ & $-3.45 \pm 1.22$ & $-11.30 \pm 5.36$ & $-15.70 \pm 3.39$ & $-9.97 \pm 11.89$ & $-26.12 \pm 5.68$ & $-17.06 \pm 7.98$ \\
\hline
\end{tabular}


Table 2

\begin{tabular}{ccccc}
\hline Lipid : $o$-carborane & \multicolumn{2}{c}{ Before } & After & PDI \\
\hline (a) DPPC & & PDI & $d / \mathrm{nm}$ & \\
$1: 40$ & $262.0 \pm 191.8$ & $0.44 \pm 0.33$ & $394.9 \pm 385.2$ & $0.71 \pm 0.30$ \\
$1: 20$ & $139.3 \pm 37.6$ & $0.41 \pm 0.12$ & $170.4 \pm 62.5$ & $0.31 \pm 0.10$ \\
$1: 10$ & $100.7 \pm 18.4$ & $0.21 \pm 0.06$ & $120.2 \pm 26.1$ & $0.35 \pm 0.20$ \\
$1: 1$ & $86.3 \pm 4.6$ & $0.26 \pm 0.22$ & $93.7 \pm 4.8$ & $0.19 \pm 0.08$ \\
$1: 0.5$ & $83.4 \pm 5.5$ & $0.24 \pm 0.02$ & $106.1 \pm 15.1$ & $0.16 \pm 0.01$ \\
$1: 0$ & $61.0 \pm 19.5$ & $0.30 \pm 0.18$ & $113.3 \pm 28.8$ & $0.43 \pm 0.32$ \\
\hline (b) DSPC & & & & \\
$1: 40$ & $3917.2 \pm 3614.7$ & $0.46 \pm 0.16$ & $2225.4 \pm 1839.2$ & $0.51 \pm 0.44$ \\
$1: 20$ & $2335.6 \pm 2707.4$ & $0.57 \pm 0.44$ & $3062.1 \pm 3838.5$ & $0.57 \pm 0.43$ \\
$1: 10$ & $1802.1 \pm 2347.4$ & $0.61 \pm 0.45$ & $287.2 \pm 187.7$ & $0.42 \pm 0.22$ \\
$1: 1$ & $245.0 \pm 165.6$ & $0.52 \pm 0.35$ & $95.7 \pm 4.4$ & $0.23 \pm 0.13$ \\
$1: 0.5$ & $82.3 \pm 5.5$ & $0.09 \pm 0.02$ & $93.1 \pm 4.8$ & $0.27 \pm 0.07$ \\
$1: 0$ & $76.0 \pm 2.6$ & $0.15 \pm 0.13$ & $900.4 \pm 698.1$ & $0.74 \pm 0.45$
\end{tabular}

Table 3

\begin{tabular}{ccccc}
\hline & & \multicolumn{2}{c}{ Mean $d / \mathrm{nm}$} \\
Time / days & DPPC unloaded & DPPC loaded & DSPC unloaded & DSPC loaded \\
\hline 1 & $86.4 \pm 24.8$ & $121.4 \pm 26.7$ & $83.3 \pm 20.6$ & $130.9 \pm 26.2$ \\
19 & $89.0 \pm 37.2$ & $103.2 \pm 20.4$ & $87.0 \pm 24.0$ & $108.3 \pm 21.5$ \\
35 & $83.6 \pm 22.1$ & $101.0 \pm 28.0$ & $66.5 \pm 16.2$ & $108.7 \pm 22.6$ \\
49 & $85.7 \pm 21.4$ & $62.0 \pm 22.7$ & $58.5 \pm 15.4$ & $89.4 \pm 20.4$ \\
63 & $77.4 \pm 25.2$ & $35.3 \pm 11.2$ & $100.0 \pm 36.2$ & $113.0 \pm 22.2$ \\
\hline
\end{tabular}

Table 4.

\begin{tabular}{llll}
\hline & & Mean $\pm \mathrm{SD}$ & \\
Lipid : $o$-carborane & $d / \mathrm{nm}$ & PDI & $\zeta / \mathrm{mV}$ \\
\hline (a) DPPC & & & \\
0 & $63.3 \pm 28.9$ & $0.20 \pm 0.02$ & $0.02 \pm 0.83$ \\
$1: 0.5$ & $65.8 \pm 31.2$ & $0.31 \pm 0.09$ & $-0.21 \pm 0.91$ \\
$1: 1$ & $67.5 \pm 29.4$ & $0.21 \pm 0.04$ & $-1.71 \pm 0.95$ \\
$1: 10$ & $73.8 \pm 28.1$ & $0.26 \pm 0.09$ & $-13.33 \pm 10.14$ \\
$1: 20$ & $82.6 \pm 24.5$ & $0.16 \pm 0.01$ & $-14.78 \pm 10.77$ \\
$1: 40$ & $87.6 \pm 31.1$ & $0.19 \pm 0.01$ & $-16.78 \pm 9.65$ \\
\hline (b) DSPC & & & \\
0 & $71.9 \pm 11.7$ & $0.38 \pm 0.00$ & $-4.55 \pm 4.55$ \\
$1: 0.5$ & $74.9 \pm 15.3$ & $0.29 \pm 0.14$ & $-3.81 \pm 5.00$ \\
$1: 1$ & $77.2 \pm 16.0$ & $0.41 \pm 0.04$ & $0.38 \pm 0.33$ \\
$1: 10$ & $88.9 \pm 11.5$ & $0.41 \pm 0.08$ & $-20.00 \pm 4.53$ \\
$1: 20$ & $97.7 \pm 19.0$ & $0.29 \pm 0.19$ & $-12.70 \pm 17.39$ \\
$1: 40$ & $100.7 \pm 21.3$ & $0.32 \pm 0.05$ & $-11.09 \pm 15.29$ \\
\hline
\end{tabular}



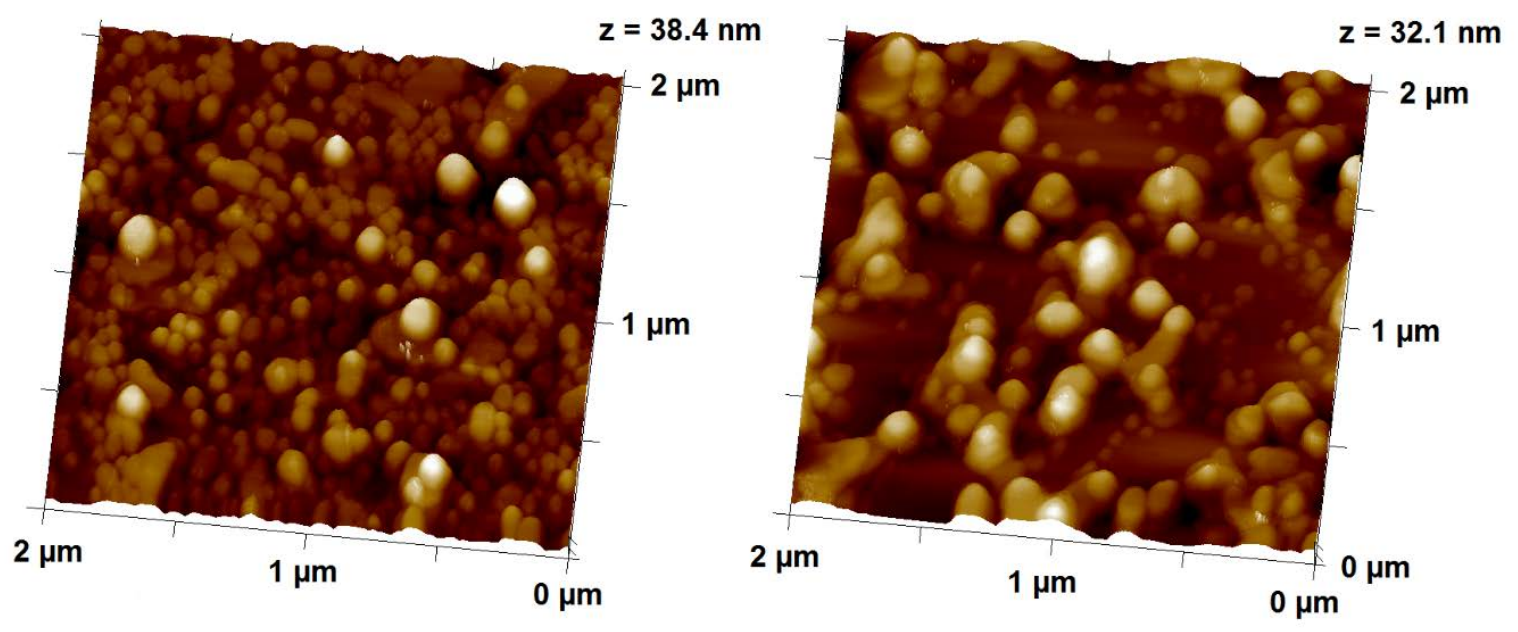

a

b

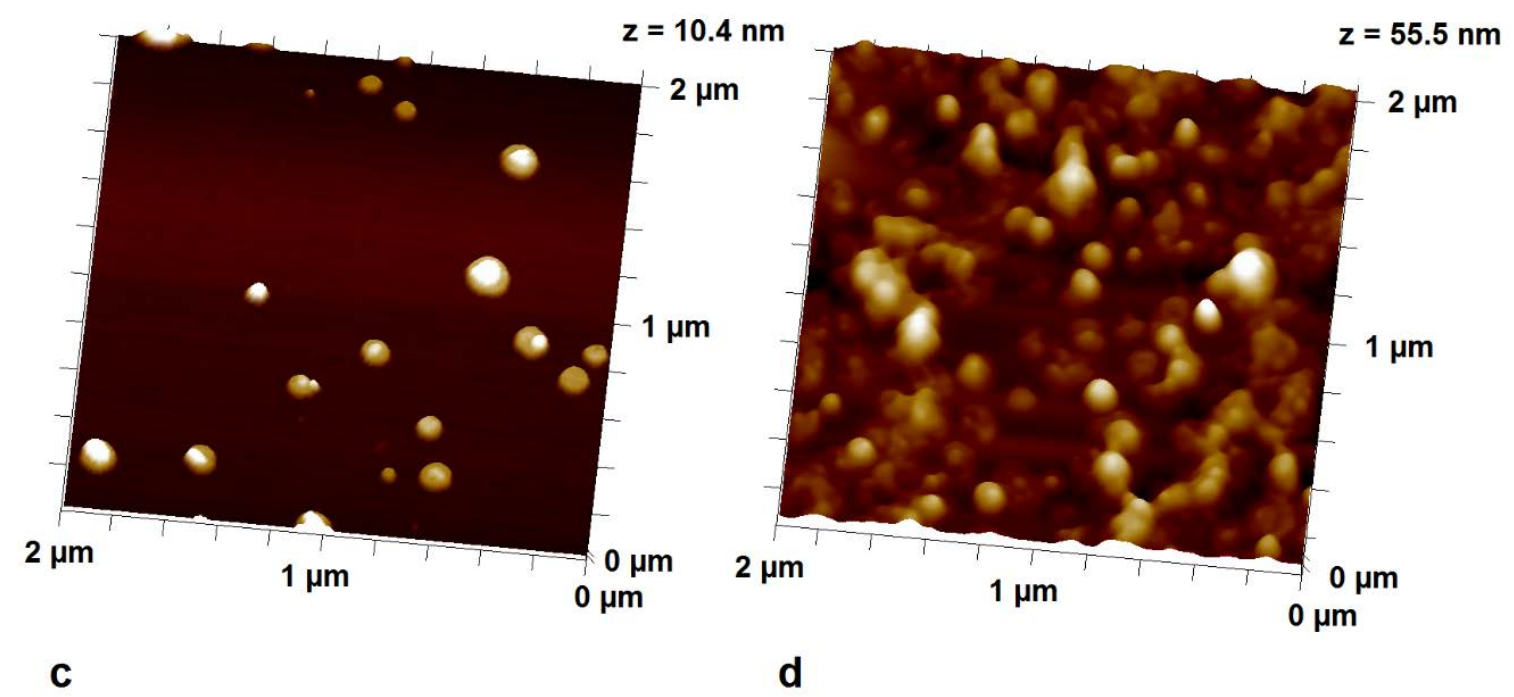

Fig. 1. 


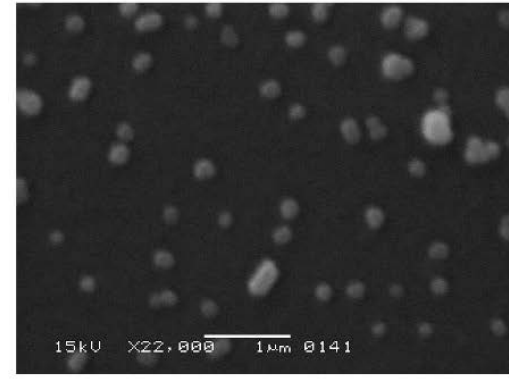

a

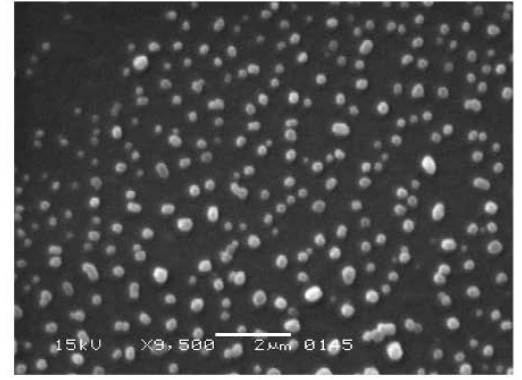

d

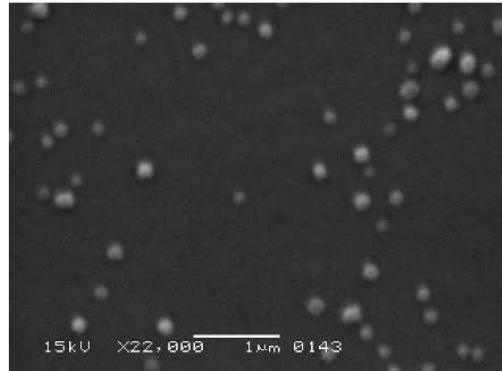

b

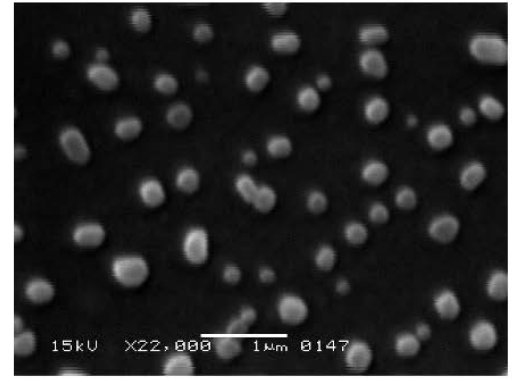

e

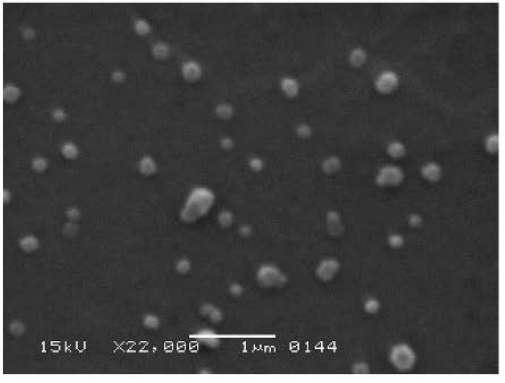

C

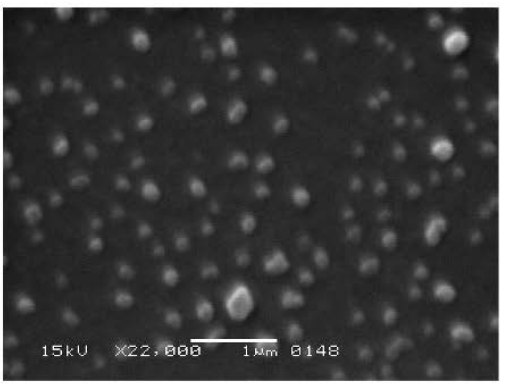

f

Fig. 2. 


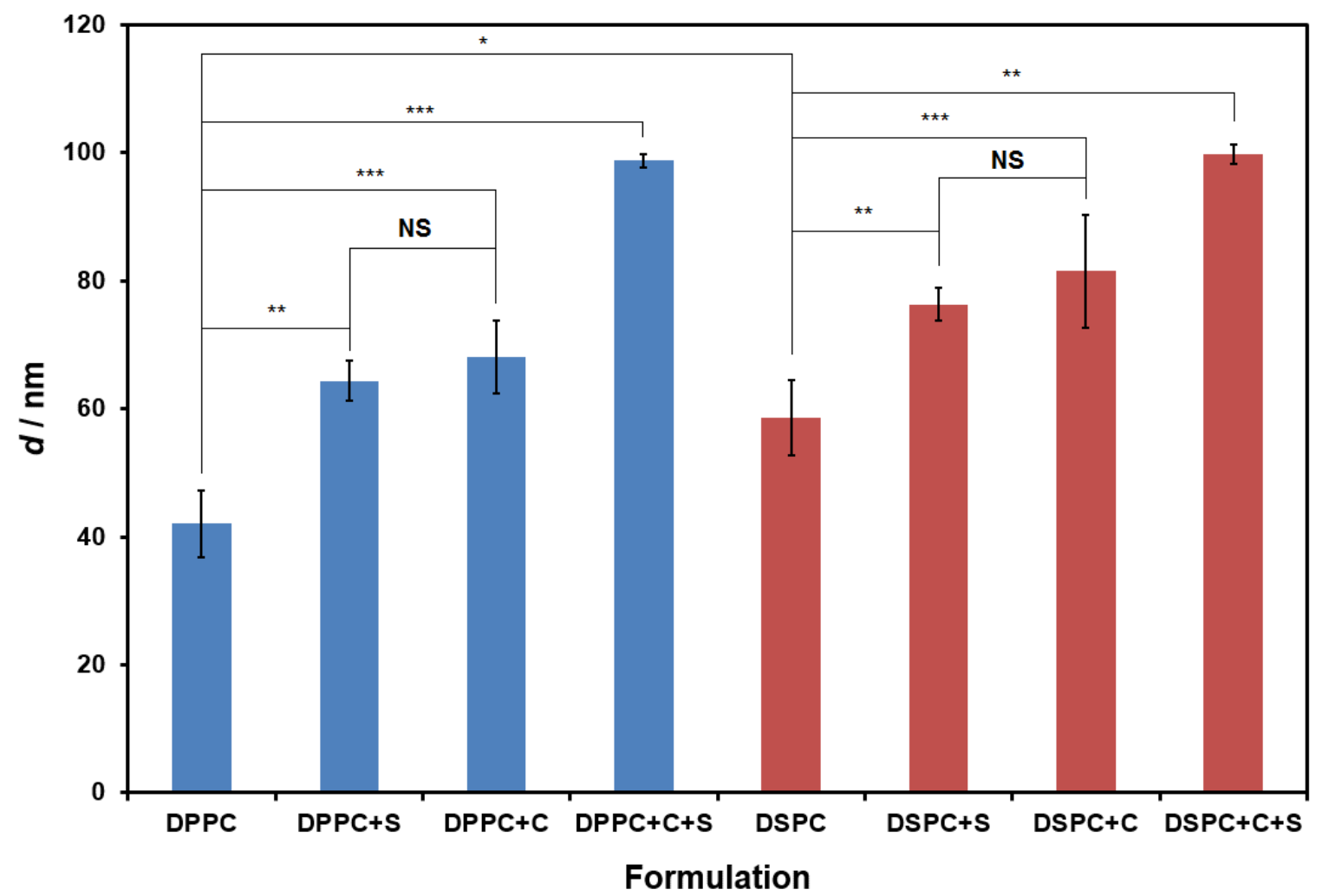

Fig. 3. 


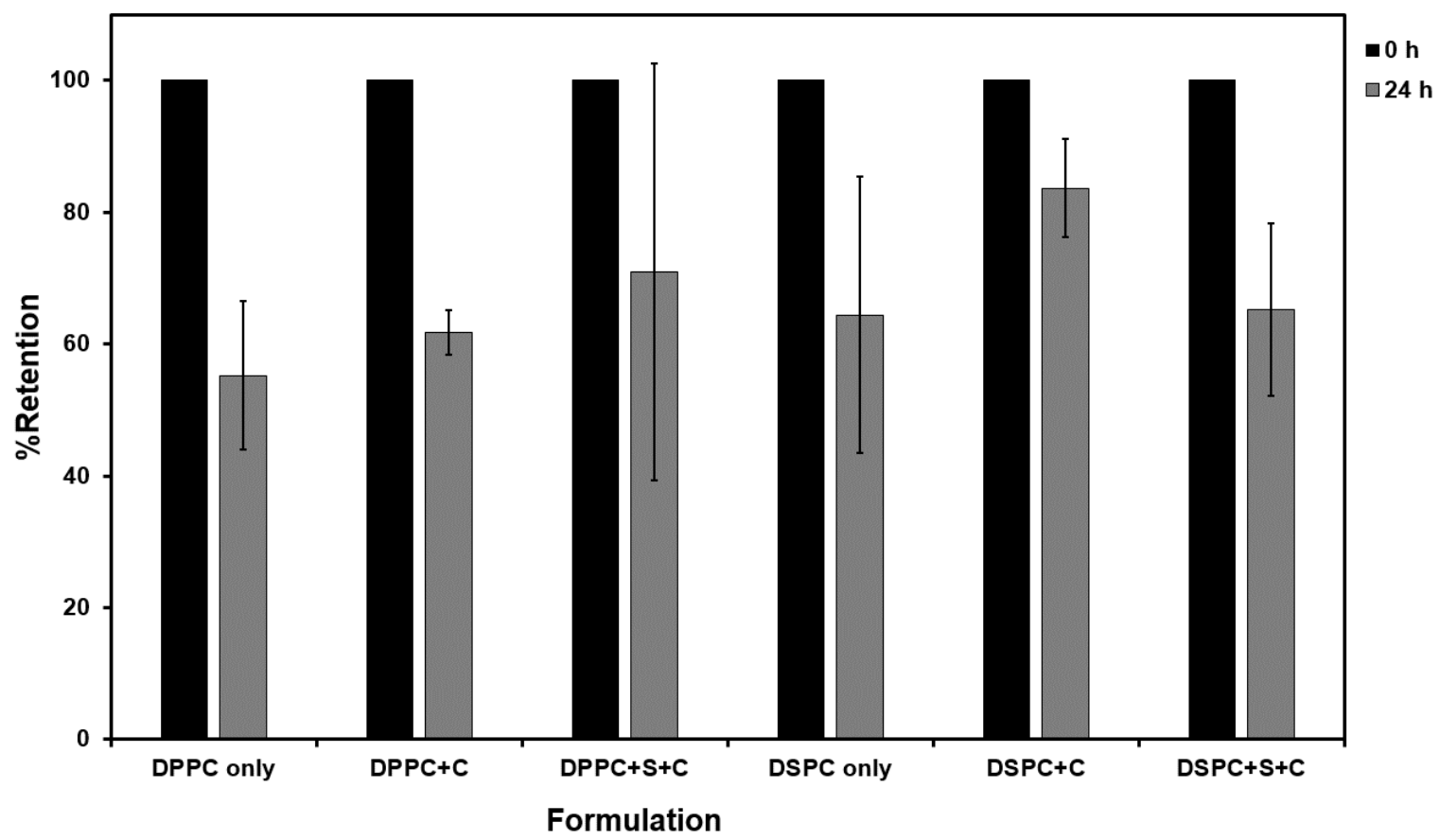

Fig. 4. 

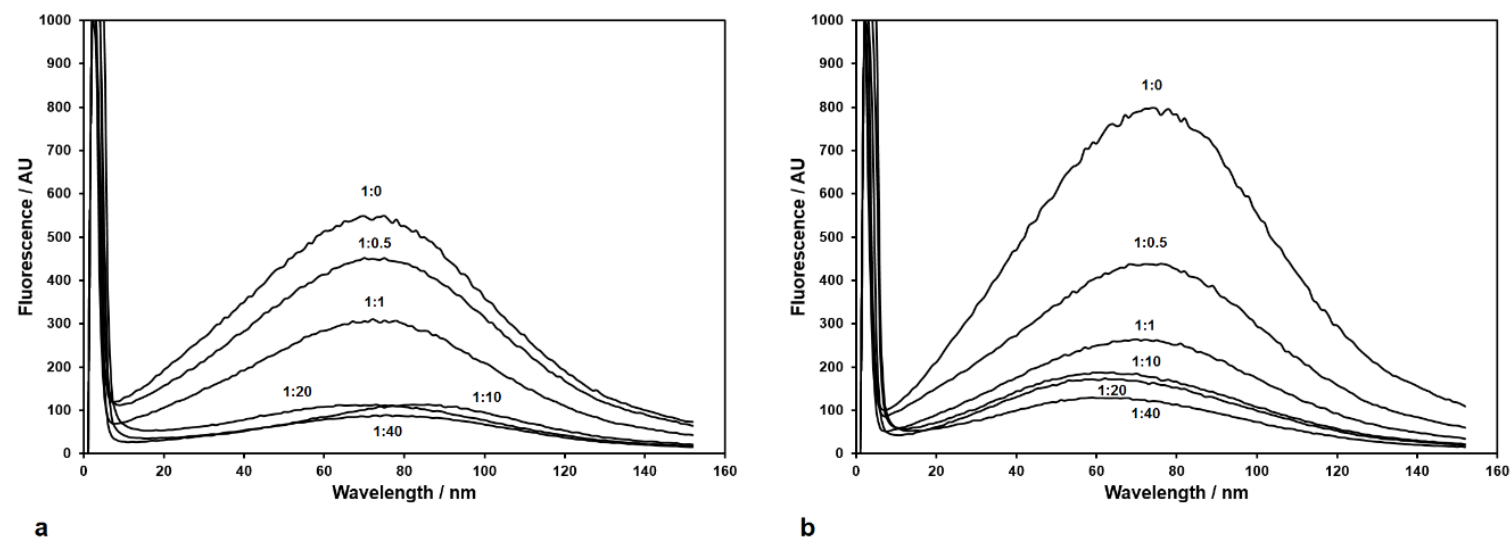

Fig. 5. 


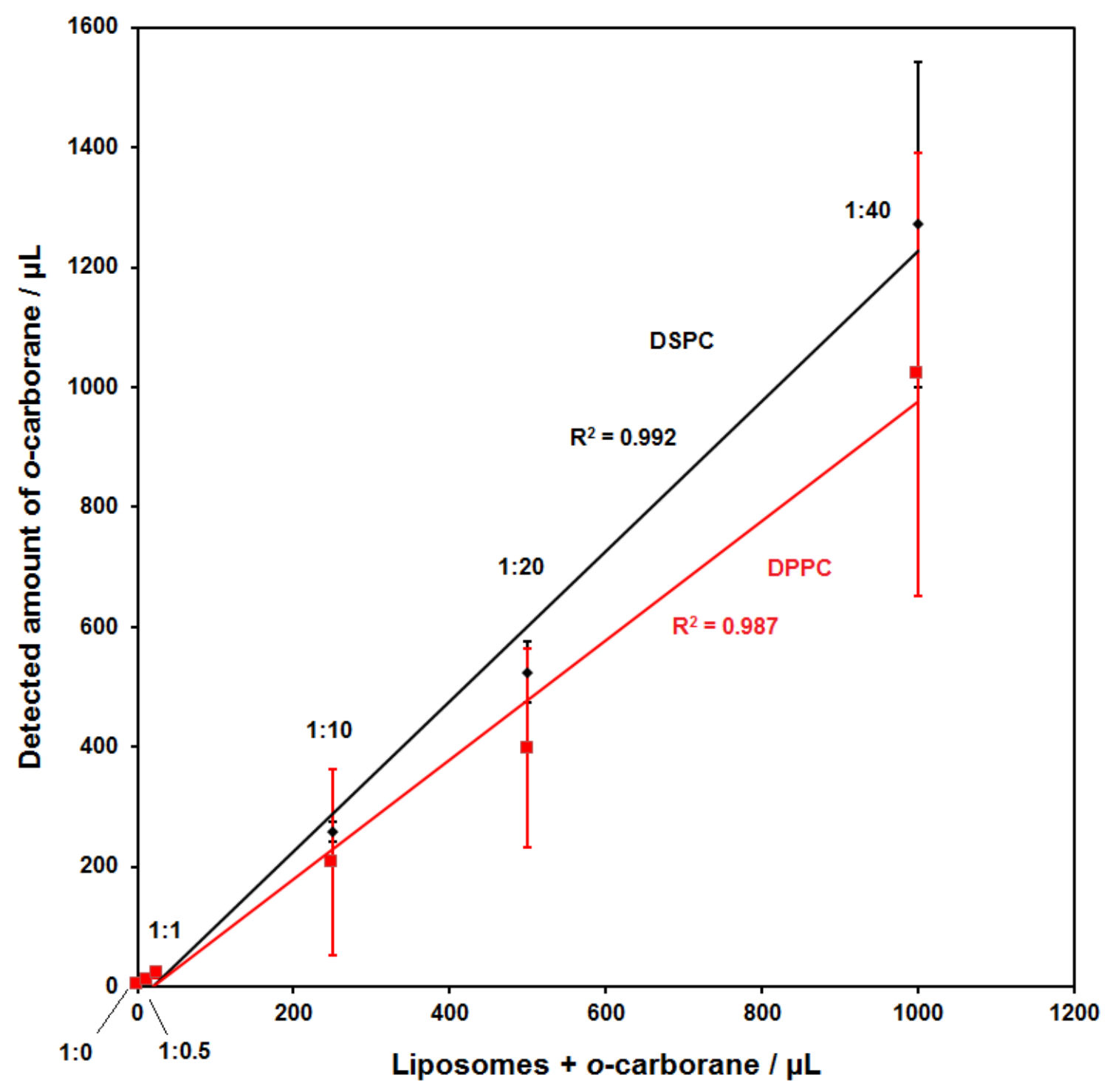

Fig. 6. 